\title{
Artificial Intelligence Assisted Prediction of COVID-19 Hotspots In Third Wave Using EHTERAZ
}

\section{CAM}

Faculty and PostDoc, Information and Communication Technologies (ICT)
Mustafa Ahmed ${ }^{1}$, Mohammed Houkan ${ }^{1}$, Kishor Kumar Sadasivuni, ${ }^{1}{ }^{*}$

Center for Advanced Materials, Qatar University

kishor_kumars@yahoo.com

\section{Abstract}

The present study conceptualize fusion of Artificial Intelligence and contract tracking mobile application for predicting the COVID-19 hot spots. The findings suggest that mobile technology can be used to provide real-time data on the national and local state of the pandemic, enabling policy makers to make informed decisions in a quickly moving pandemic.

Keywords: Artificial Intelligence; Covid-19; EHTERAZ

Why should we think now?

The State of Qatar has announced the gradual lifting of COVID-19 restrictions. It could lead to enter a new wave of the spread of the Corona virus. In this proposal an Al Based solution will be presented which will help to prediction of Hotspots of Coivd-19 in Qatar by using EHTERAZ App.

\section{List of Events}

Amir Cup Handball Championship 2020- 2021

$\square$ The 4th Cultural Diversity Festival

$\square$ Total CAF Super Cup 2020

FIFA World Cup 2022 and AFC Asian Cup 2023 qualifiers

$\square$ Amir Cup Final 2021

$\square$ FIFA Arab Cup 2021

$\square$ Souq Waqif Spring Festival

$\square$ Darb Al Saai

$\square$ Qatar National Day 2021

$\square$ FIFA World Cup 2022

$\square$ All these events, many human gatherings are expected specially FIFA Arab Cup 2021and FIFA World Cup 2022. One or more infected people in these gatherings can spread the virus significantly

\section{EHTERAZ Data}

By getting some data from EHTERAZ such as; mobile location, Bluetooth range, EHTERAZE status(Vaccinated, Recovered, Infected), the derived density of areas. By using machine learning model, the system will predict future high-risk areas based on data derived from EHTERAZ.

\section{Data set}

$>$ Age

$>$ Previously Infected with COVID-19

$>$ Frequent Visiting area

$>$ Person in contact

$>$ Vaccinated

$>$ Number of vaccinated people in area

$>$ Number of non-vaccinated people in area

$>$ Number of COIVD-19 cases in area

$>$ COIVD-19 cases hospitalization

$>$ and death rate in area

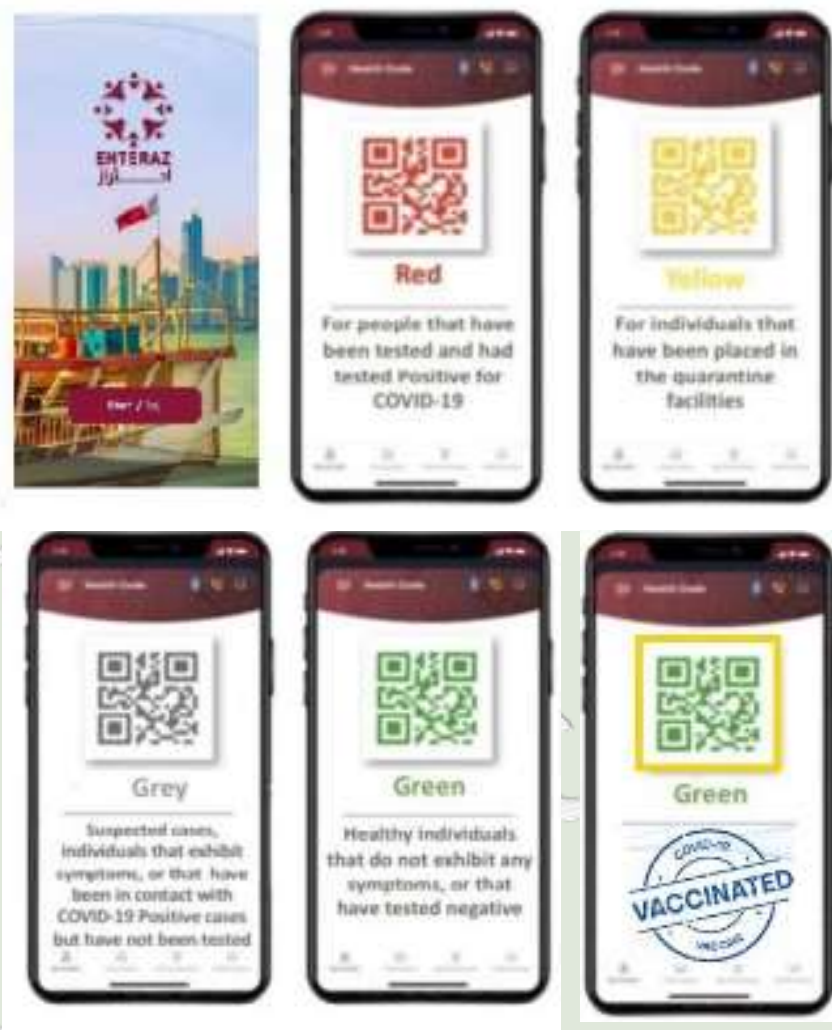

\section{Proposed Al Schematic}

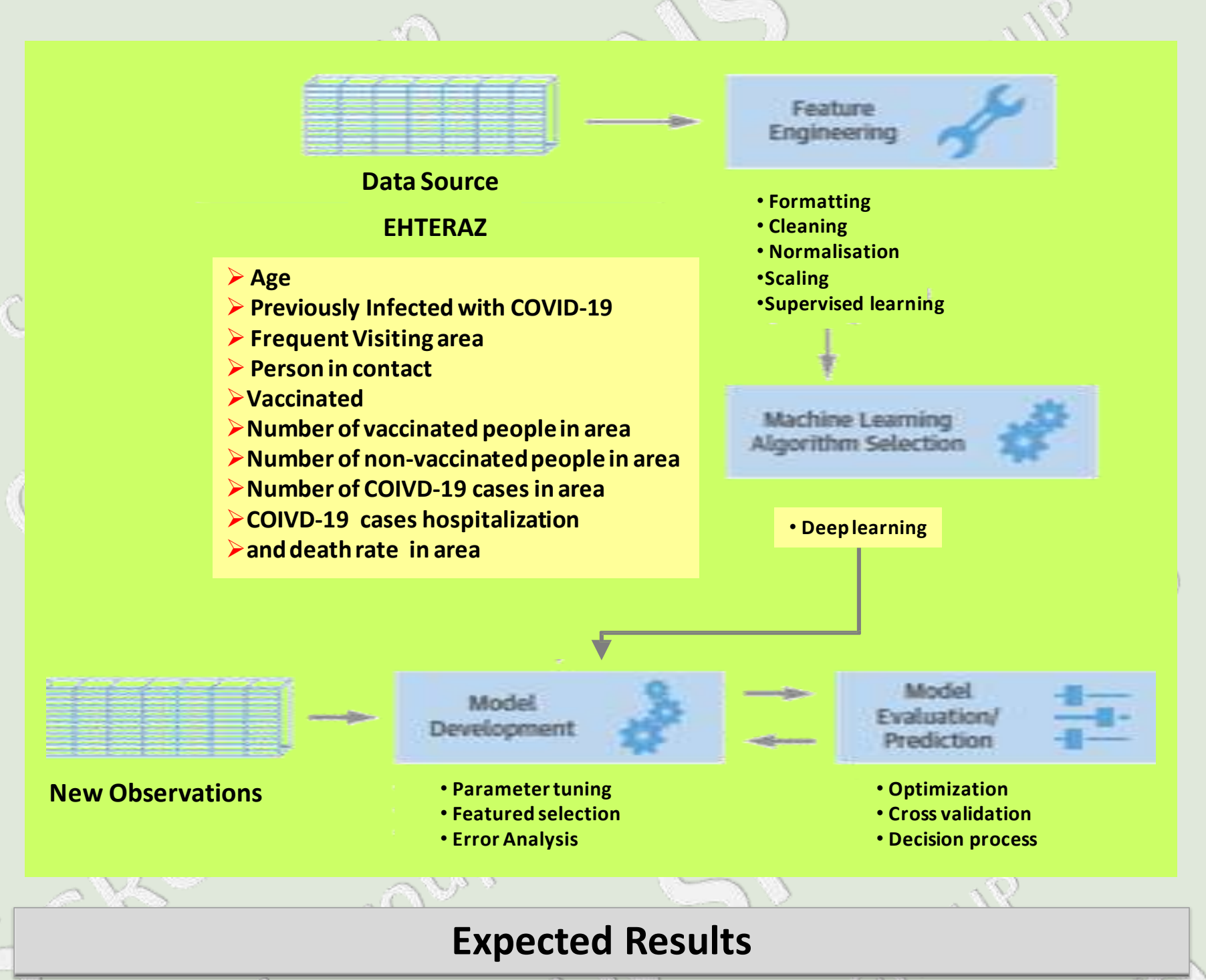

An Al based map which shows the future Covid-19 Hotspots based on date derived from EHTERAZ. The hotspot areas will be classified according to the expected degree of risk.

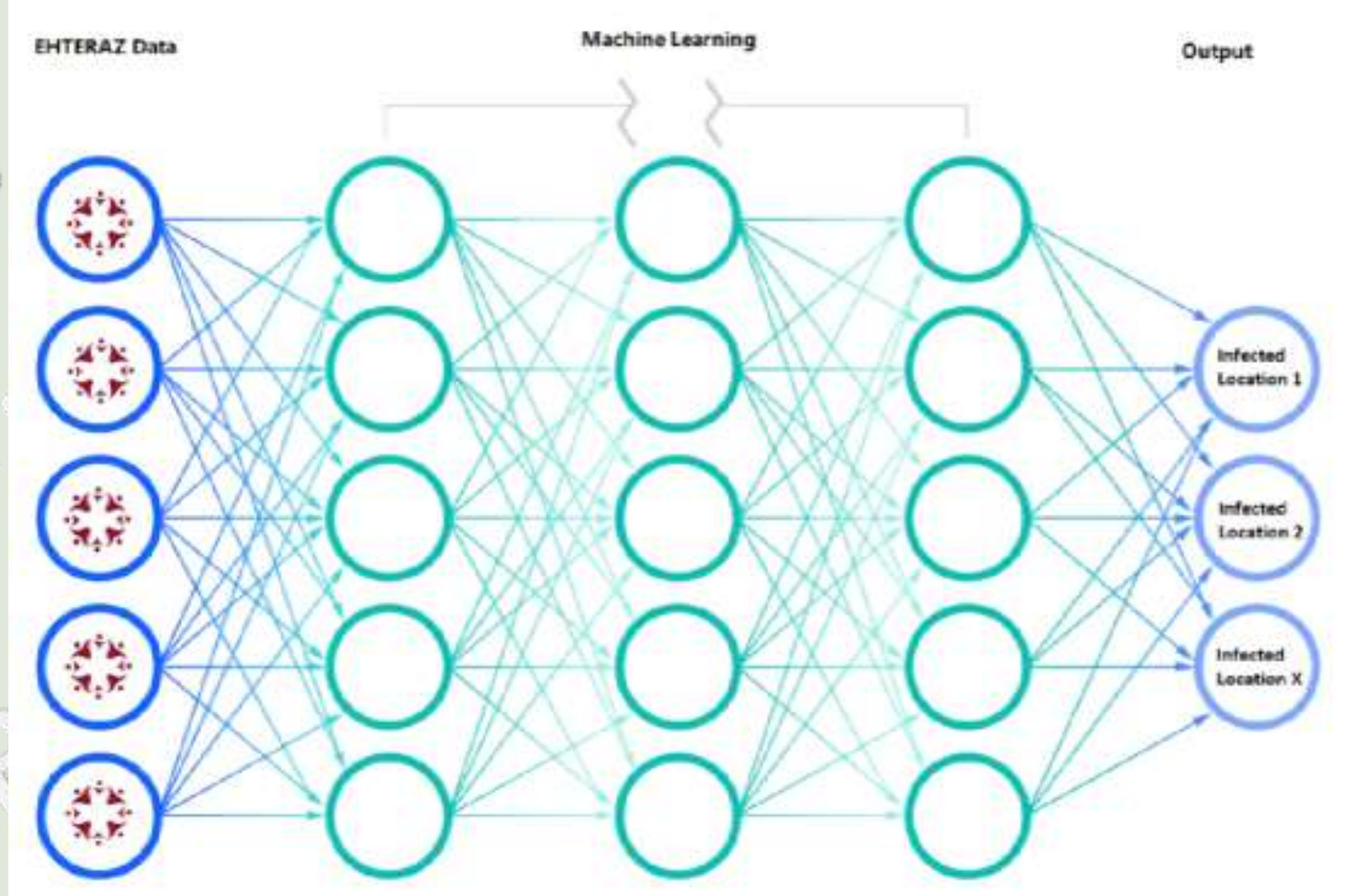

